\title{
openheart Elevated serum levels of cardiovascular biomarkers are associated with progression of renal cancer
}

\author{
Takao Kamai, Yuumi Tokura, Toshitaka Uematsu, Kazumasa Sakamoto, \\ Issei Suzuki, Kohei Takei, Takahiro Narimatsu, Tsunehito Kambara, Hideo Yuki, \\ Hironori Betsunoh, Hideyuki Abe, Yoshitatsu Fukabori, Masahiro Yashi, \\ Ken-Ichiro Yoshida
}

To cite: Kamai T, Tokura Y, Uematsu T, et al. Elevated serum levels of cardiovascular biomarkers are associated with progression of renal cancer. Open Heart 2018;5:e000666. doi:10.1136/ openhrt-2017-000666

Received 30 May 2017 Revised 17 November 2017 Accepted 27 November 2017

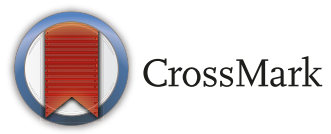

Department of Urology, Dokkyo Medical University, Mibu, Tochigi, Japan

\section{Correspondence to} Dr Takao Kamai, Department of Urology Dokkyo Medical University Mibu Tochigi Japan ; kamait@dokkyomed.ac.jp

\section{ABSTRACT}

Objective Renal cell carcinoma (RCC) is a hypervascular tumour due to high constitutive production of vascular endothelial growth factor (VEGF), which is activated by hypoxia-inducible factor (HIF). Elevated levels of cardiovascular peptides, including brain natriuretic peptide (BNP), have been reported in patients with cancer, regardless of whether they have overt cardiovascular disease. Furthermore, it has been demonstrated that hypoxia stimulates BNP production by an HIF-dependent manner. However, the clinical implications of such cardiovascular peptides in patients with RCC have not been assessed.

Methods In patients with clear cell RCC who underwent nephrectomy, we investigated the relationship between the serum level of BNP or N-terminal pro-BNP (NT-proBNP) and various clinicopathological characteristics, including serum VEGF and expression of BNP and HIF-2 alpha in the primary tumour.

Results Elevated preoperative serum levels of BNP, NTproBNP and VEGF, as well as increased tumour expression of HIF-2 alpha, were associated with a worse performance status, local invasion, distant metastasis and shorter overall survival. HIF-2 alpha expression showed a positive correlation with the preoperative serum VEGF level, while there was no relation between the serum levels of BNP/ NT-proBNP and VEGF or tumour expression of HIF-2 alpha. BNP expression was very low in both tumour tissues and normal kidney tissues. Serum levels of BNP, NT-proBNP and VEGF all decreased significantly after nephrectomy. Conclusions Our findings suggested that the preoperative serum levels of BNP and NT-proBNP are markers of tumour progression, as well as indicators of subclinical functional and structural myocardial damage in patients with advanced RCC.

\section{INTRODUCTION}

The 'hallmarks of cancer' are considered to include tumour angiogenesis, evasion of the host immune response and increased glucose uptake (aerobic glycolysis, the Warburg effect), and these issues are all currently attracting attention in the oncology field. ${ }^{1}$ Renal cell carcinoma (RCC) is characteristically a highly angiogenic and immunogenic

\section{Key questions}

What is already known about this subject?

- Renal cell carcinoma (RCC) is a hypoxia-inducible factor (HIF)/vascular endothelial growth factor (VEGF)-dependent angiogenic and hypervascular tumour. Elevated levels of cardiovascular peptides, including brain natriuretic peptide (BNP), have been reported in patients with cancer, regardless of whether they have overt cardiovascular disease. On the other hand, it has been demonstrated that hypoxia stimulates BNP production by an HIF-dependent manner.

What does this study add?

- This study shows that higher preoperative serum levels of BNP, N-terminal pro-BNP (NT-proBNP) and VEGF, as well as elevated HIF-2 alpha expression in the primary tumour, were associated with a worse performance status, local invasion, distant metastasis and shorter overall survival. However, BNP expression was very low in RCC tissues and normal kidney tissues, and there was no relationship between serum levels of BNP/ NT-proBNP and serum VEGF or tumour expression of HIF-2 alpha. Moreover, serum levels of BNP and NT-proBNP decreased significantly after tumour resection. These observations suggested that RCC itself might have some influence on such damage, if so, the decrease of serum BNP and NT-proBNP after tumour resection in patients with RCC might be associated with alleviation of stress on the heart.

How might this impact on clinical practice?

- These clinical findings suggested that the preoperative serum levels of BNP and NT-proBNP are related to progression of RCC. Since cancer cachexia is potentially accompanied by cardiac wasting, and BNP and NT-proBNP both decrease after nephrectomy, we should pay attention to the possibility of subclinical functional and structural damage to the myocardium in advanced RCC and provide insight into the cardiac defence mechanisms against the effects of cancer progression. 
tumour with increased aerobic glycolysis. Clear cell RCC (ccRCC) accounts for approximately $80 \%$ of all RCCs and is a hypervascular tumour due to high constitutive production of vascular endothelial growth factor (VEGF) that promotes the growth of specific tumour vasculature. ${ }^{2}$ It is well known that von Hippel-Lindau (VHL) acts as a driver gene in ccRCC, ${ }^{3}$ with loss of heterozygosity of $V H L$ being found in more than $90 \%$ of sporadic ccRCCs. ${ }^{4}$ VHL gene dysfunction leads to inhibition of hypoxia-inducible factor (HIF) prolyl hydroxylase ${ }^{56}$ As a result, HIF remains unhydroxylated and avoids degradation, thus upregulating the transcription of several genes involved in angiogenesis and cell proliferation, including VEGF and platelet-derived growth factor. VEGF is a potent angiogenic protein with a key role in tumour angiogenesis, ${ }^{7}$ which exerts its effects by binding to the VEGF receptor on endothelial cells. ${ }^{8}$ Thus, RCC is considered to be an HIF/VEGF-dependent cancer, and its elevated angiogenic potential results in the development of highly vascular tumours. ${ }^{2}$

Cancer cachexia is a multifactorial syndrome characterised by the ongoing loss of skeletal muscle mass (with or without loss of fat mass) that cannot be fully reversed by conventional nutritional support and leads to progressive functional impairment. ${ }^{9-14}$ The association between cancer cachexia and cardiac wasting is also well characterised. ${ }^{15}$ Cardiac cachexia is a complex clinical syndrome, which has a poor prognosis in the terminal stage of chronic heart failure. ${ }^{16}$ Natriuretic peptides, such as brain natriuretic peptide (BNP) and amino N-terminal pro-BNP

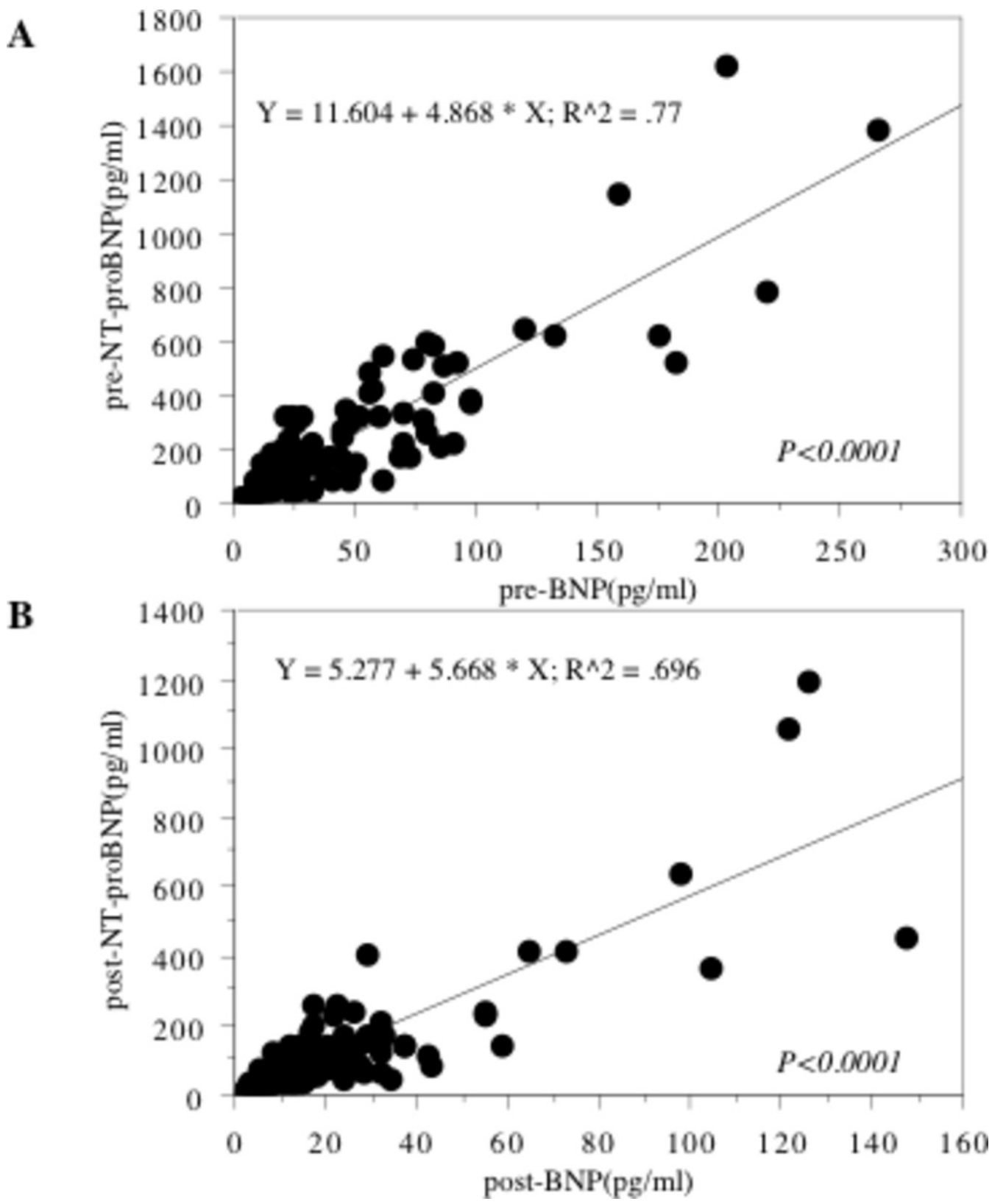

Figure 1 Spearman's rank correlation between BNP and NT-proBNP. The serum levels of BNP are positively related with those of NT-proBNP preoperatively (A) and postoperatively (B). BNP, brain natriuretic peptide; NT-proBNP, N-terminal pro-BNP. 
Table 1 Relationship between molecules and clinicopathological features

\begin{tabular}{|c|c|c|c|c|c|c|c|c|}
\hline & \multirow{2}{*}{$\begin{array}{l}\text { Preoperative } \\
\text { BNP (pg/mL) } \\
\text { Mean } \pm \text { SD }\end{array}$} & \multirow[b]{2}{*}{$P$ value } & \multirow{2}{*}{$\begin{array}{l}\text { Preoperative NT- } \\
\text { proBNP }(\mathrm{pg} / \mathrm{mL}) \\
\text { Mean } \pm \text { SD }\end{array}$} & \multirow[b]{2}{*}{ P value } & \multirow{2}{*}{$\begin{array}{l}\text { HIF-2 } \\
\text { alpha } \\
\text { Mean } \pm \text { SD }\end{array}$} & \multirow[b]{2}{*}{$P$ value } & \multirow{2}{*}{$\begin{array}{l}\text { Preoperative } \\
\text { VEGF }(\mathrm{pg} / \mathrm{mL}) \\
\text { Mean } \pm S D\end{array}$} & \multirow[b]{2}{*}{$P$ value } \\
\hline & & & & & & & & \\
\hline All patients $(n=129)$ & $44.2 \pm 47.9$ & & $227.5 \pm 261.5$ & & $5.1 \pm 4.9$ & & $173.1 \pm 211.9$ & \\
\hline \multicolumn{9}{|c|}{$\begin{array}{l}\text { Karnofsky performance } \\
\text { status }\end{array}$} \\
\hline$>80 \%(\mathrm{n}=93)$ & $40.3 \pm 50.0$ & $4 \mathrm{E}-04$ & $198.2 \pm 265.4$ & $4 \mathrm{E}-04$ & $3.3 \pm 4.0$ & $<0.0001$ & $124.3 \pm 164.8$ & $<0.0001$ \\
\hline$<80 \%(\mathrm{n}=36)$ & $56.3 \pm 38.7$ & & $321.2 \pm 234.6$ & & $7.6 \pm 4.2$ & & $364.1 \pm 256.1$ & \\
\hline \multicolumn{9}{|c|}{$\begin{array}{l}\text { Hypertension, arrhythmia or } \\
\text { diabetes mellitus }\end{array}$} \\
\hline Positive $(n=71)$ & $37.2 \pm 42.4$ & 0.018 & $190.9 \pm 221.1$ & 0.035 & $4.1 \pm 3.6$ & 0.3496 & $157.6 \pm 183.8$ & 0.0946 \\
\hline Negative $(n=58)$ & $52.5 \pm 53.4$ & & $267.2 \pm 302.5$ & & $5.2 \pm 5.2$ & & $212.5 \pm 189.4$ & \\
\hline \multicolumn{9}{|l|}{ Grade } \\
\hline $1(n=10)$ & $23.4 \pm 25.7$ & 0.015 & $129.0 \pm 90.5$ & 0.013 & $2.4 \pm 2.6$ & $<0.0001$ & $40.9 \pm 38.3$ & $<0.0001$ \\
\hline $2(n=63)$ & $36.8 \pm 43.9$ & & $164.9 \pm 208.6$ & & $3.0 \pm 2.5$ & & $102.2 \pm 119.6$ & \\
\hline $2(n=47)$ & $57.1 \pm 54.3$ & & $297.2 \pm 300.3$ & & $7.3 \pm 12.2$ & & $333.7 \pm 248.6$ & \\
\hline $4(n=9)$ & $63.1 \pm 49.2$ & & $382.1 \pm 352.8$ & & $11.7 \pm 3.0$ & & $566.6 \pm 123.8$ & \\
\hline \multicolumn{9}{|l|}{ pT } \\
\hline $1 / 2(n=59)$ & $28.9 \pm 33.2$ & $2 \mathrm{E}-04$ & $113.7 \pm 79.5$ & $<0.0001$ & $2.6 \pm 2.3$ & $<0.0001$ & $84.0 \pm 95.3$ & 0.0005 \\
\hline $3 / 4(n=70)$ & $55.7 \pm 53.9$ & & $315.2 \pm 316.9$ & & $6.4 \pm 5.1$ & & $291.6 \pm 251.3$ & \\
\hline \multicolumn{9}{|c|}{ Distant metastasis (M) } \\
\hline M0 $(n=80)$ & $34.7 \pm 44.7$ & $<0.0001$ & $174.4 \pm 254.9$ & $<0.0001$ & $3.6 \pm 3.7$ & 0.0002 & $139.7 \pm 193.2$ & $<0.0001$ \\
\hline$M 1(n=49)$ & $60.1 \pm 49.2$ & & $327.4 \pm 250.8$ & & $6.5 \pm 5.2$ & & $277.0 \pm 234.5$ & \\
\hline
\end{tabular}

BNP, brain natriuretic peptide; HIF-2, hypoxia-inducible factor 2; NT-proBNP, N-terminal pro-BNP; VEGF, vascular endothelial growth factor.

(NT-proBNP), are regulators of ventricular function that are widely used as diagnostic biomarkers in the treatment of pathophysiological heart conditions and in the management of heart failure ${ }^{17-22}$ Recently, elevated levels of various cardiovascular peptides, including BNP, have been reported in patients with cancer without any clinical manifestations of cardiac disease. ${ }^{2324}$ We have sometimes encountered elevated serum levels of BNP and/or NT-proBNP in patients with RCC irrespective of whether they have heart disease. However, the clinical association between cardiovascular biomarkers and RCC has not yet been fully assessed. It has been demonstrated that hypoxia stimulates BNP production, which is induced in an HIF-dependent manner. ${ }^{25}$ Because RCC is an HIF/VEGF-dependent cancer, ${ }^{2}$ it is important to study the serum levels of BNP and NT-proBNP in patients with RCC, as well as serum VEGF and expression of BNP and HIF in the primary tumour. Obtaining such information will help shed more light on the clinical implications of elevated serum levels of cardiovascular hormones in patients with cancer.

\section{METHODS}

\section{Study population}

The serum levels of BNP (normal $<18.4 \mathrm{pg} / \mathrm{mL}$ ) and NT-proBNP (normal $<135 \mathrm{pg} / \mathrm{mL}$ ) were retrospectively investigated in 129 patients (81 men and 48 women) with histopathologically confirmed RCC who underwent nephrectomy at our centre between 2011 and 2015. All patients routinely underwent imaging (CT and/or MRI) for preoperative tumour staging prior to nephrectomy. The following patients were excluded: patients who had received any prior cardiotoxic therapy and patients who had any symptoms of unstable cardiac disease, systemic inflammatory disease or autoimmune disease.

Cardiovascular risk factors were recorded, such as hypertension, arrhythmia, diabetes mellitus and smoking, and medications were documented. The cardiac status was considered to be normal with no requirement for medical assessment or treatment in patients who had no cardiac symptoms or ECG abnormalities, with a BNP level $<100 \mathrm{pg} / \mathrm{mL}$ and NT-proBNP level $<400 \mathrm{pg} / \mathrm{mL} .{ }^{26}$ Otherwise, echocardiography was performed by a cardiologist to investigate potential cardiac disorders. Significant echocardiographical findings were defined as slightly, moderately or severely reduced LV or RV function, moderate or severe valvular disease, or diastolic dysfunction with a pseudonormal or restrictive filling pattern. Patients were defined as having an abnormal cardiac status if there was a history of heart disease or ECG abnormalities, regardless of the echocardiographical findings, or if significant echocardiographical findings were associated with a BNP level $\geq 100 \mathrm{pg} / \mathrm{mL}$ and/or an NT-proBNP level $\geq 400 \mathrm{pg} / \mathrm{mL}$. 
A

BNP (25-36 kDa)

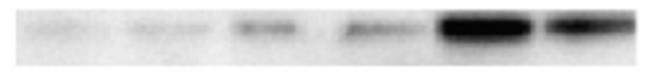

Beta-actin (42 kDa)

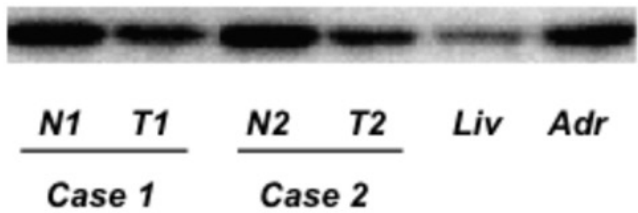

B

HIF-2 alpha (120 kDa)

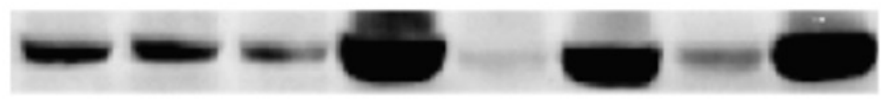

Beta-actin (42 kDa)

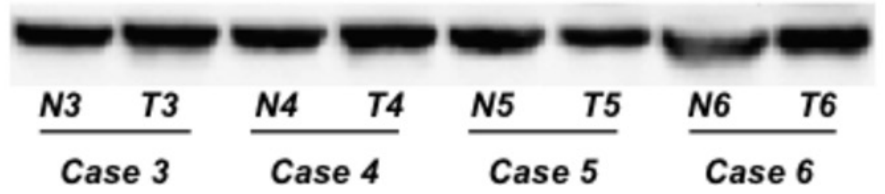

Figure 2 Expression of phosphorylated BNP, HIF-2 alpha and beta actin proteins in the primary tumour tissues using western blotting. BNPs were lower expressed in the primary tumours and in normal kidney than those in normal liver and adrenal ground tissues (A). HIF-2 alpha is increased expressed in the tumours than in normal kidney (B). Each number corresponds to a case number. Adr, normal adrenal gland; BNP, brain natriuretic peptide; HIF-2, hypoxia-inducible factor 2; Liv, normal liver; M, marker; N, non- tumour tissue; T, primary tumour tissue.

We routinely measured the serum levels of BNP and NT-proBNP 1 week before nephrectomy and 4 weeks after surgery, as well as performing a full blood examination and biochemical tests. VEGF was measured in serum samples obtained from the patients and stored at $-80^{\circ} \mathrm{C}$ until analysis by using an ELISA kit for human VEGF (DVE00, R\&D Systems, MN). The tumour grade and clinical stage were determined according to the Fuhrman system and the TNM (tumour, node, metastases) classification, respectively. ${ }^{27} 28$ The postoperative follow-up period ranged from 3 to 83 months (median: 31 months).

\section{Western blotting}

Western blotting of tissue samples from all of the resected primary tumours was performed as described previously. ${ }^{29}$ In order to compensate for variation of BNP and HIF-2 alpha expression, tumour tissue samples and corresponding non-neoplastic tissues from the same patient were compared. Proteins bands were visualised by chemiluminescence. Densitometry was performed with a Power Doppler Imaging (PDI) imaging scanner (Agfa Japan, Tokyo) and data analysis using NIH Image software (ImageJ for Mac OS, V.1.47). The antibodies employed were a mouse anti-human antibody targeting BNP (BNP (D-8), sc-271185; Santa Cruz Biotechnology, Santa Cruz, CA), a rabbit anti-human antibody targeting HIF-2 alpha (HIF-2 alpha (D9E3), No 7096; Cell Signaling Technology, Danvers, MA) and a beta-actin antibody (No 1501R; Millipore, Bedford, MA).

\section{Statistical analysis}

Statistical analysis was performed using the MannWhitney $\mathrm{U}$ test to compare two groups and the KruskalWallis test to compare three or four groups. Spearman's rank correlation coefficient analysis was performed to determine the relations between two groups. Cause-specific survival curves were drawn by the Kaplan-Meier method and differences of survival were examined by using the log-rank test. The impact of several factors on survival was assessed by univariate and multivariate Cox proportional hazards analysis. In all analyses, $\mathrm{P}<0.05$ was considered to indicate significance.

\section{RESULTS}

\section{Correlation between serum BNP and NT-proBNP in patients} with RCC

The preoperative serum level of BNP showed a positive correlation with that of NT-proBNP $\left(\mathrm{r}^{2}=0.77, \mathrm{P}=0.0001\right.$, figure 1A). Similarly, the postoperative serum levels of BNP and NT-proBNP were correlated $\left(r^{2}=0.69, \mathrm{P}=0.0001\right.$, figure 1B).

\section{Elevation of preoperative serum BNP and NT-proBNP in advanced RCC}

Elevated preoperative serum levels of BNP and NT-proBNP were associated with a worse Karnofsky performance status (KPS), undifferentiated tumour histology, local invasion and a larger tumour mass (T3/4) and distant metastasis (M1) (table 1). Patients with hypertension, 

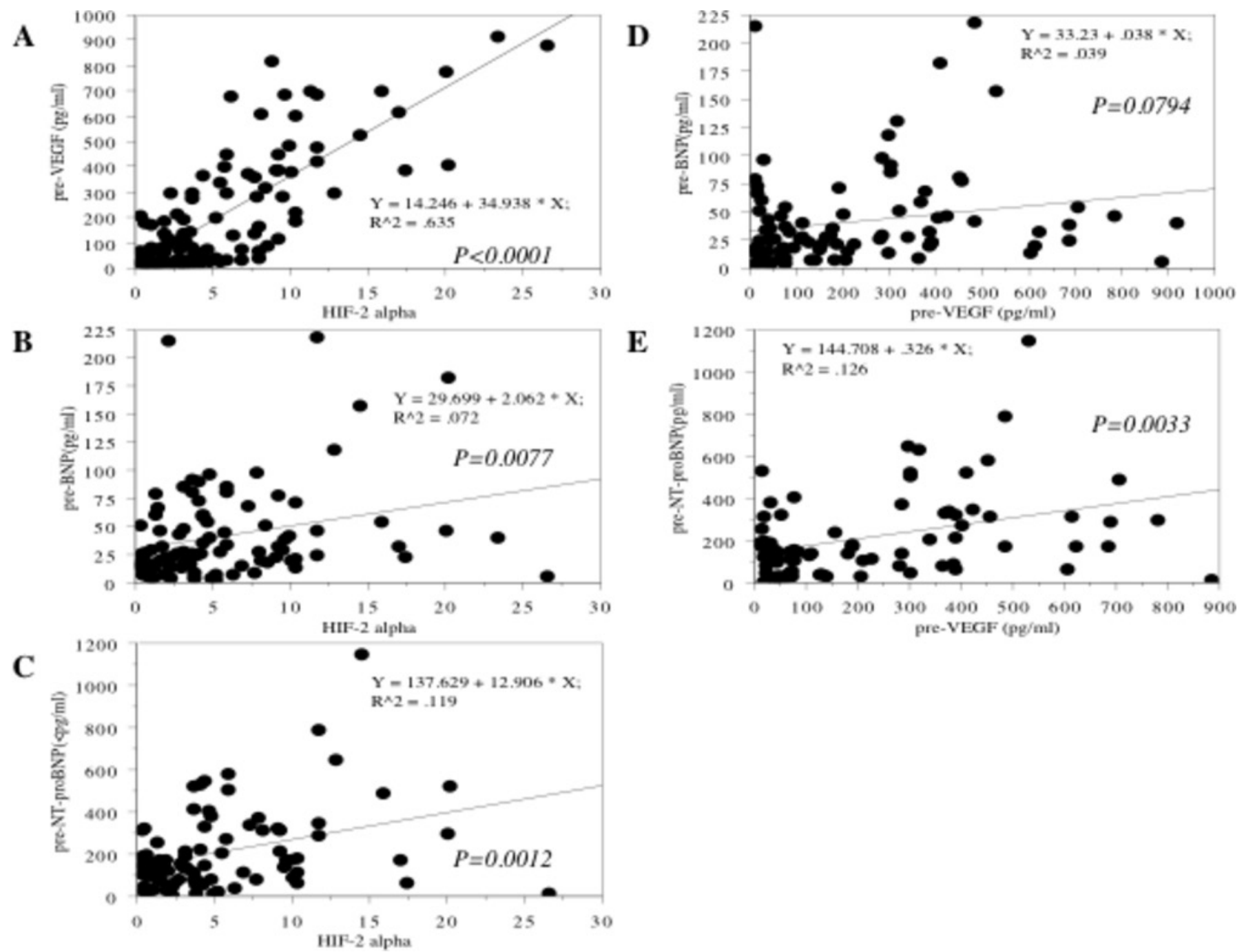

Figure 3 Spearman's rank correlation between preoperative serum levels of BNP/NT-proBNP and expression of HIF-2 alpha and preoperative serum level of VEGF. There was a positive relationship between expression levels of HIF-2 alpha in the primary tumour and preoperative serum levels of VEGF (A). Expressions levels of HIF-2 alpha in the primary tumours did not correlate with preoperative serum levels of BNP (B) and NT-proBNP (C). There were no relationships between preoperative serum levels of VEGF and BNP (D) and NT-proBNP (E). BNP, brain natriuretic peptide; HIF-2, hypoxia-inducible factor 2; NTproBNP, N-terminal pro-BNP; VEGF, vascular endothelial growth factor.

diabetes mellitus and/or arrhythmia had higher preoperative serum levels of BNP and NT-proBNP (table 1).

\section{Increased tumour tissue expression of HIF-2 alpha, but not BNP}

Expression of BNP was very low in the primary tumours and in normal kidney tissues compared with the positive control (normal adrenal gland and liver tissues, figure 2A). In contrast, HIF-2 alpha was more highly expressed in the tumours than in normal kidney tissues. The level of HIF-2 alpha expression in the primary tumour was associated with a lower KPS, less differentiated histology, local invasion and a metastatic profile, while the level of HIF-2 alpha expression in the primary tumour was not influenced by the existence of hypertension, diabetes mellitus and/or arrhythmia (figure 2B, table 1).

\section{No relation of serum BNP and NT-proBNP to HIF expression or the serum VEGF level}

There was a positive correlation between expression of HIF-2 alpha and the preoperative serum VEGF level $\left(\mathrm{r}^{2}=0.63, \mathrm{P}<0.0001\right.$, figure $\left.3 \mathrm{~A}\right)$. On the other hand, preoperative serum levels of BNP and NT-proBNP were not related to expression of HIF-2 alpha or to the preoperative serum VEGF level (table 1, figure 3B-E). Furthermore, elevation of the preoperative VEGF level was associated with a lower KPS, undifferentiated tumour histology, local invasion and a larger tumour mass (T3/4) and distant metastasis (M1) (table 1).

\section{Decrease of serum BNP, NT-proBNP and VEGF after surgery}

The serum levels of BNP, NT-proBNP and VEGF decreased after surgery (mean \pm SD: BNP from $44.2 \pm 261.5$ to 23.7 $\pm 25.6, \quad \mathrm{P}<0.0001$; NT-proBNP from 227.5 \pm 261.5 to 
A

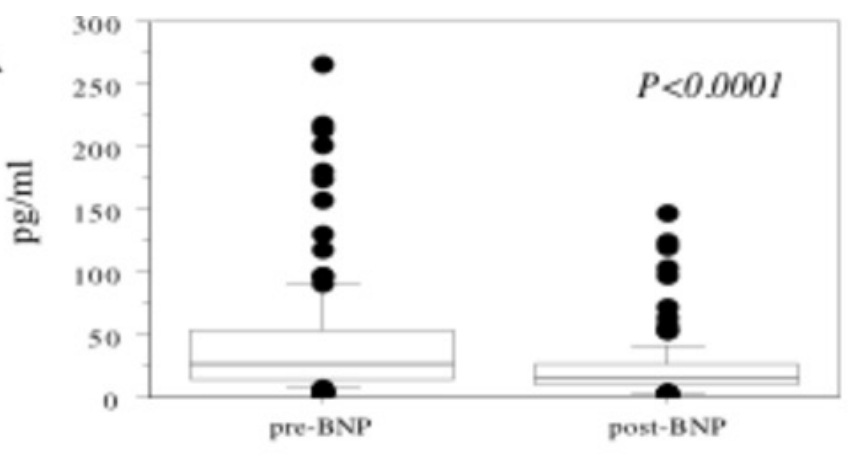

B

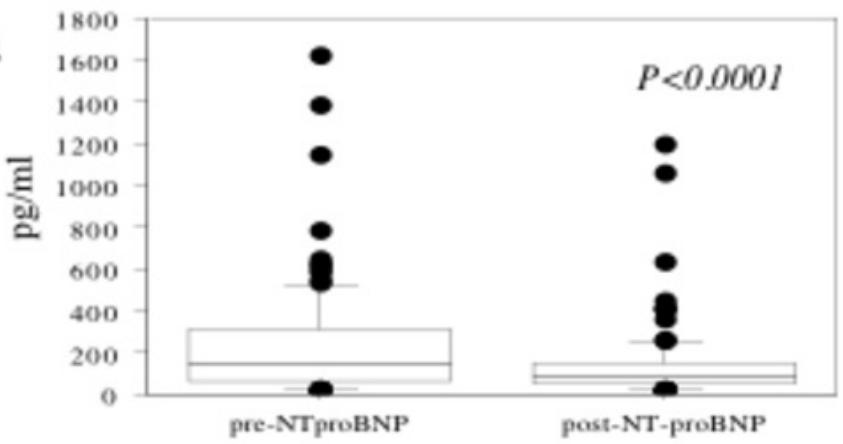

C

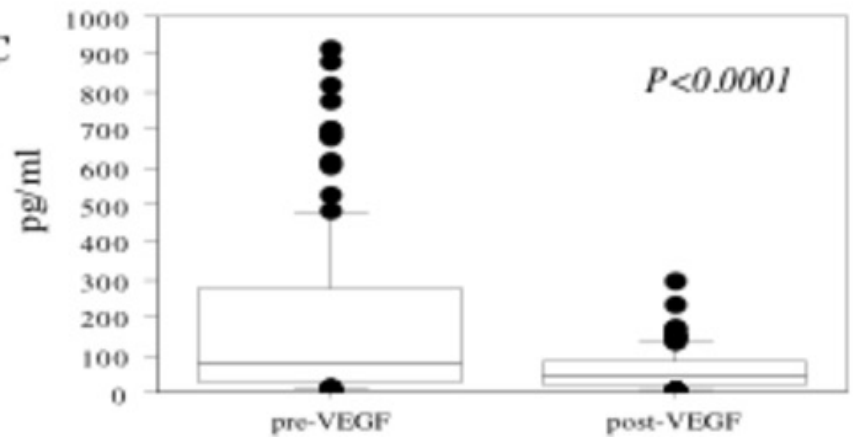

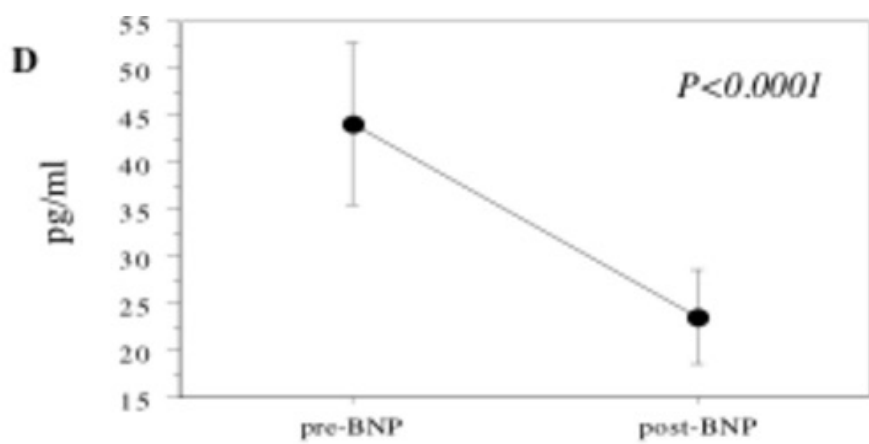

E

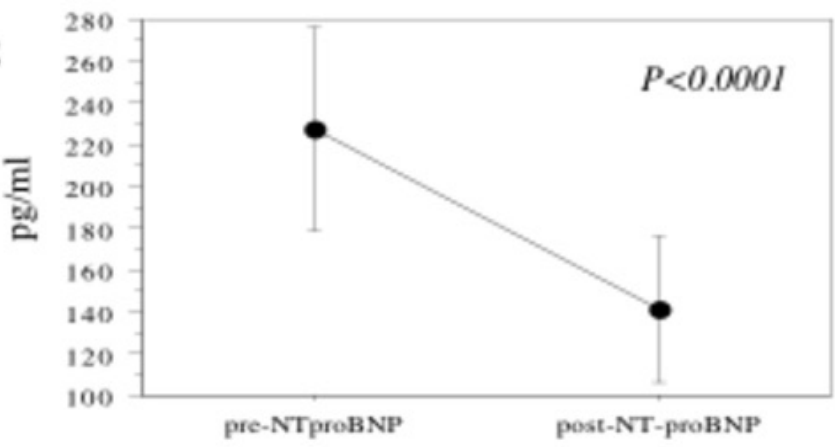

F

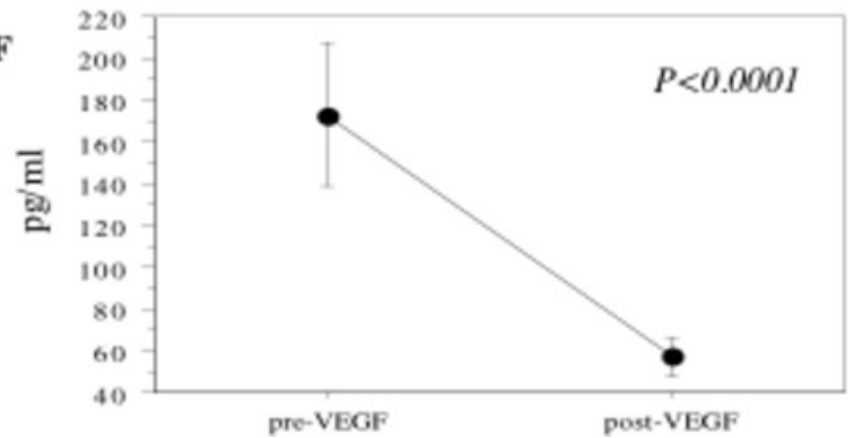

Figure 4 Changing of serum levels after tumour resection. Preoperative serum levels of BNP (A), NT-proBNP (B) and VEGF (C) significantly decreased in patients with renal cell carcinoma (RCC) after tumour resection. The median value is the central line, the box is the IQR, the bars are the full range and the points are the outliers. (D-F) The data show the $95 \% \mathrm{Cl}$. BNP, brain natriuretic peptide; NT-proBNP, N-terminal pro-BNP; VEGF, vascular endothelial growth factor.

$141.1 \pm 177, \mathrm{P}=0.0018$; and VEGF from $173.1 \pm 211.9$ to $57.3 \pm 53.1, \mathrm{P}<0.0001$, figure 4$)$. When the rate of decrease of BNP after tumour resection compared with the level before surgery ( (preoperative serum level-postoperative serum level)/preoperative serum level) was examined, patients with a lower KPS, less differentiated histology (grade 3/4), higher stage (T3/4) and metastasis (M1) showed a larger rate of decrease (table 2). Similarly, patients with distant metastasis (M1) showed a larger rate of decrease of NT-proBNP and those with a higher stage (T3/4) tended to have a larger rate of decrease (table 2).

\section{Relationship between serum BNP or NT-proBNP and survival}

The median preoperative serum level of BNP was 34.9, so the patients were divided into two groups at this cut-off value. Kaplan-Meier analysis showed that a higher BNP level was associated with a shorter overall survival time (figure 5A). Similarly, a higher NT-proBNP level (median: 178.8) was associated with shorter overall survival (figure 5B). Furthermore, patients with higher median preoperative serum levels of HIF-2 alpha (median: 3.3) and VEGF (median: 73.3) displayed unfavourable overall survival (figure 5C,D).

When we divided the patients into two groups by the median postoperative serum level of BNP (median: 16.9), NT-proBNP (median: 91.5) or VEGF (median: 40.3), Kaplan-Meier analysis showed that patients with higher BNP or VEGF levels had worse overall survival than those with lower levels ( $\mathrm{P}=0.009$ and $\mathrm{P}<0.0001$, respectively). In addition, patients with higher postoperative NT-proBNP levels tended to show unfavourable overall survival $(\mathrm{P}=0.0613)$.

Univariate Cox analysis showed that shorter overall survival was associated with the preoperative serum levels of BNP, NT-proBNP, and VEGF, HIF-2 alpha expression in the primary tumour, histological grade, metastasis, and the postoperative serum levels of BNP, NT-proBNP and 
Table 2 Decreased ratio of BNP and NT-proBNP after tumour resection

\begin{tabular}{|c|c|c|c|c|}
\hline & $\Delta \mathrm{BNP}(\%)^{*}$ & & $\Delta$ NT-proBNP $(\%)^{*}$ & \\
\hline & Mean \pm SD & $P$ value & Mean \pm SD & P value \\
\hline Total $(n=129)$ & $38.2 \pm 32.8$ & & $27.9 \pm 39.7$ & \\
\hline Karnofsky performance & & & & \\
\hline$>80 \%(n=78)$ & $34.2 \pm 35.4$ & 0.0120 & $24.1 \pm 43.3$ & 0.1262 \\
\hline$<80 \%(n=23)$ & $51.0 \pm 18.0$ & & $40.0 \pm 21.8$ & \\
\hline Grade & & & & \\
\hline $1 / 2(n=73)$ & $31.4 \pm 35.6$ & 0.0030 & $24.7 \pm 40.6$ & 0.3012 \\
\hline $3 / 4(n=56)$ & $47.6 \pm 26.1$ & & $32.1 \pm 38.6$ & \\
\hline pT & & & & \\
\hline $1 / 2(n=71)$ & $28.9 \pm 38.3$ & 0.0031 & $20.7 \pm 42.8$ & 0.0575 \\
\hline $3 / 4(n=58)$ & $45.8 \pm 25.7$ & & $33.6 \pm 36.5$ & \\
\hline Distant metastasis (M) & & & & \\
\hline M0 $(n=80)$ & $32.5 \pm 37.5$ & 0.0076 & $21.8 \pm 45.3$ & 0.0303 \\
\hline M1 $(n=49)$ & $49.6 \pm 15.8$ & & $40.3 \pm 20.5$ & \\
\hline Decreased ratio $(\Delta)^{*}=$ & $\frac{\text { preoperative-p }}{\text { preopera }}$ & rum level & & $\times 100(\%)$ \\
\hline
\end{tabular}

BNP, brain natriuretic peptide; NT-proBNP, N-terminal pro-BNP.

VEGF. However, only histological grade had a significant impact on survival according to multivariate analysis, and metastasis tended to have an influence (table 3).

\section{DISCUSSION}

This retrospective study showed that patients with higher preoperative serum levels of BNP and NT-proBNP had the following clinicopathological characteristics in comparison to patients with lower preoperative serum levels: (1) a lower KPS; (2) less differentiated tumours with more local invasion and metastasis; and (3) a worse prognosis. We also found that the serum BNP and NT-proBNP levels decreased after radical nephrectomy. Furthermore, there was little expression of BNP in either RCC tissues or normal kidney tissues, while HIF-2 alpha was highly expressed in RCC tissues. Moreover, there was a positive correlation between expression of HIF-2 alpha in the primary tumour and the preoperative serum level of VEGF. Higher expression of HIF-2 alpha and an increased serum level of VEGF were significantly associated with a lower KPS, a less differentiated, locally invasive and metastatic tumour profile, and an unfavourable prognosis, with serum VEGF decreasing after tumour resection. However, the preoperative serum levels of BNP and NT-proBNP were not correlated with HIF-2 expression by RCC or with the preoperative serum level of VEGF. These findings suggested that the preoperative serum levels of cardiovascular hormones (such as BNP and NT-proBNP) might be related to progression of RCC and a worse prognosis, but these findings also raise some questions. First, where were BNP and NT-proBNP produced? Second, why were the serum levels of BNP and NT-proBNP increased and was it in response to the existence of RCC?
First, we hypothesised that RCC might produce BNP and NT-proBNP, because the serum levels of these two hormones decreased after nephrectomy. However, we found that BNP expression was actually very low in both RCC and normal kidney tissues compared with positive control tissues (normal adrenal gland and liver). This indicated that BNP and NT-proBNP were not directly or mainly produced by either the tumours or normal kidney tissues, suggesting secretion from other organs such as the heart by a mechanism through which RCC has some effect on the myocardium. Again, this raises the question of how RCC influences the heart to increase production of BNP and NT-proBNP. Next, we considered the effect of increased HIF-2 alpha expression in the primary tumours on the serum levels of BNP and NT-proBNP.

BNP and NT-proBNP are normally secreted by atrial and/or ventricular myocardial cells in response to volume or pressure overload, and production is related to the severity of myocardial dysfunction. ${ }^{17-21}$ It is known that cancers can influence the endocrine system, altering hormone secretion to promote tumour progression and survival. ${ }^{9.10}$ Investigation of 99 consecutive patients with cancer with a BNP level $>1000 \mathrm{pg} / \mathrm{mL}$ (100 times the upper limit of normal) demonstrated that marked elevation of BNP is more frequently associated with solid tumours than with haematological malignancies, and that more than $70 \%$ of the patients with such elevated BNP levels had no signs of volume overload. ${ }^{23}$ It was also reported that elevated serum levels of BNP and high-sensitive troponin $\mathrm{T}$ were found in patients with cancer without any clinical manifestations of cardiac disease and that the levels of these cardiovascular biomarkers were higher in patients with stage 4 disease compared 


\section{A. preoperative BNP}

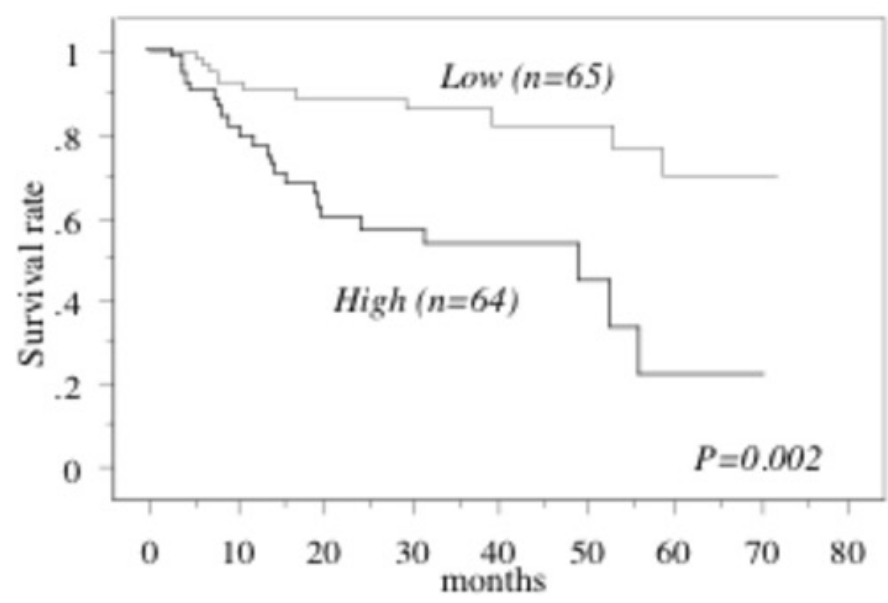

B. preoperative NT-proBNP

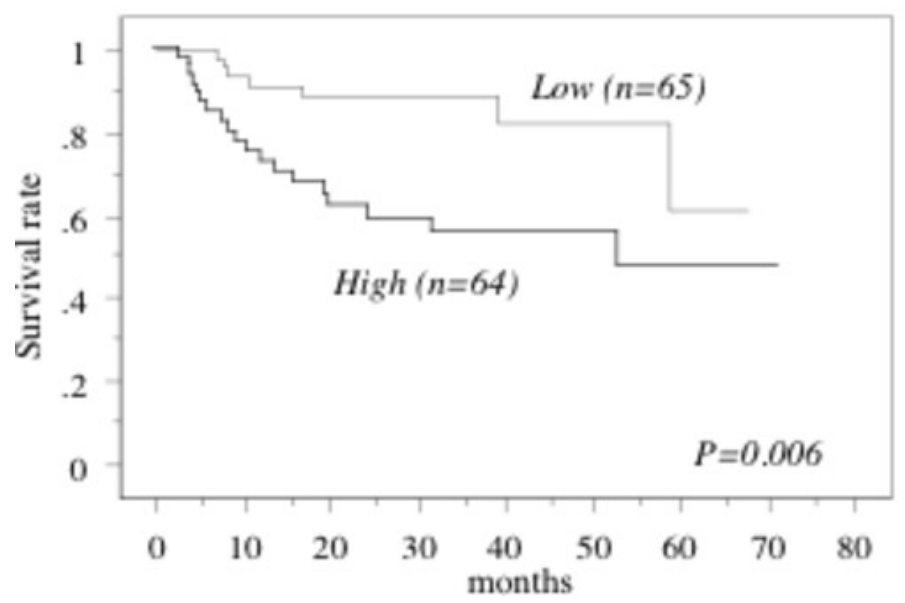

C. HIF-2 alpha

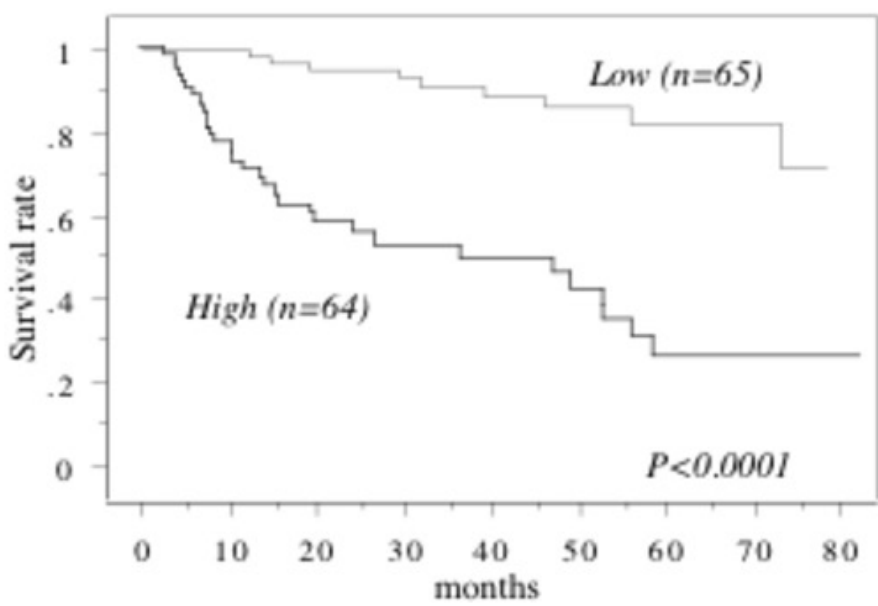

D. preoperative VEGF

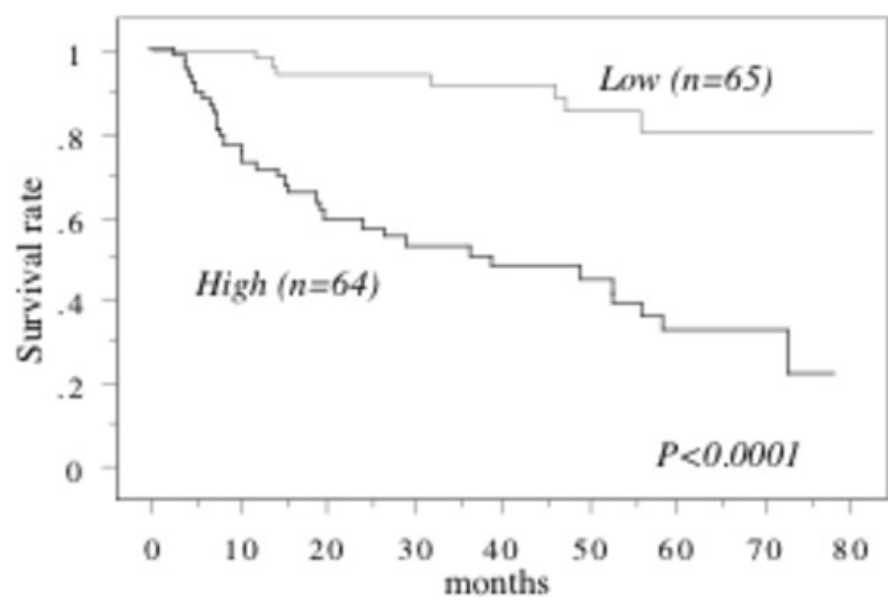

Figure 5 Overall survival in all cases. This survival curve is based on the median values of each variate in all 129 cases. The cases were divided into two groups at this level-high and low values. $\mathrm{P}$ value was analysed by log-rank test. The patients with higher preoperative serum levels of BNP (A), NT-proBNP (B) and VEGF (D), and increased expression of HIF-2 alpha (C) had shorter overall survival. BNP, brain natriuretic peptide; HIF-2, hypoxia-inducible factor 2; NT-proBNP, N-terminal pro-BNP; VEGF, vascular endothelial growth factor.

Table 3 Cox regression analysis for various potential prognostic factors in overall survival after nephrectomy

\begin{tabular}{|c|c|c|c|c|c|c|c|c|}
\hline \multirow[b]{2}{*}{ Variable } & \multirow{2}{*}{$\begin{array}{l}\text { Unfavourable/ } \\
\text { favourable } \\
\text { factors }\end{array}$} & \multirow[b]{2}{*}{$\begin{array}{l}\text { Number of } \\
\text { patients }\end{array}$} & \multicolumn{3}{|c|}{ Univariate (U) } & \multicolumn{3}{|c|}{ Multivariate (M) } \\
\hline & & & $\begin{array}{l}\text { Relative } \\
\text { risk }\end{array}$ & $95 \% \mathrm{Cl}$ & $P$ value & $\begin{array}{l}\text { Relative } \\
\text { risk }\end{array}$ & $95 \% \mathrm{Cl}$ & P value \\
\hline Pre-NT-proBNP & High/low & $64 / 65$ & 3.168 & 1.329 to 7.553 & 0.0093 & 1.221 & 0.280 to 8.746 & 0.9022 \\
\hline HIF-2 alpha & High/low & $64 / 65$ & 6.764 & 3.185 to 14.365 & $<0.0001$ & 1.146 & 0.390 to 10.076 & 0.9161 \\
\hline pT & $4,3 / 2,1$ & $58 / 71$ & 8.061 & 3.083 to 21.071 & 0.0009 & 1.248 & 0.286 to 10.530 & 0.8107 \\
\hline Metastasis & $1 / 0$ & $49 / 80$ & 8.722 & 4.025 to 18.901 & 0.0010 & 3.019 & 0.939 to 9.710 & 0.0638 \\
\hline Post-BNP & High/low & $64 / 65$ & 3.678 & 1.620 to 8.348 & 0.0018 & 6.952 & 0.585 to 82.650 & 0.1247 \\
\hline Post-NT-proBNP & High/low & $64 / 65$ & 2.126 & 0.946 to 4.774 & 0.0677 & 1.228 & 0.152 to 10.223 & 0.8137 \\
\hline
\end{tabular}

BNP, brain natriuretic peptide; HIF-2, hypoxia-inducible factor 2; NT-proBNP, N-terminal pro-BNP; VEGF, vascular endothelial growth factor. 
with earlier stages. ${ }^{24}$ Thus, elevated levels of cardiovascular biomarkers in patients with cancer have generally been considered to represent a false-positive finding. In contrast, it was recently reported that elevation of serum NT-proBNP is related to volume overload in patients with cancer, ${ }^{30}$ so the exact relationship between cancer, NT-proBNP and volume overload or left ventricular dysfunction is unclear.

Association between HIF and BNP/NT-proBNP ccRCC is a typical vascular tumour. A cardinal feature of ccRCC is a very high frequency of $V H L$ inactivation caused by deletion, mutation and/or silencing via methylation of the promoter, leading to increased expression of HIF alpha. ${ }^{31}$ HIF is an essential component of the cellular response to hypoxia. ${ }^{32}$ HIF-1 alpha expression is dependent on both raptor and rictor, and HIF-1 alpha has both proliferative and antiproliferative effects, whereas HIF-2 alpha expression only depends on rictor and it does not possess antiproliferative activity. ${ }^{33}$ Therefore, HIF-2 alpha signalling is one of the key molecular steps in tumorigenesis and progression of RCC. In the present study, higher expression of HIF-2 alpha in the primary tumour was associated with local invasion, metastasis and a worse prognosis of RCC, while preoperative serum levels of BNP and NT-proBNP were not related to HIF-2 alpha expression.

HIF-mediated induction of BNP was reported recently. Studies using human hepatoma cells and adult rat cardiomyocytes have revealed that occurrence of hypoxia in large treatment-refractory tumours is a direct and sufficient stimulus for BNP production via stabilisation of HIF alpha. ${ }^{25}$ It has also been shown that disease progression is related to a more hypoxic tumour environment, elevated expression of HIF alpha, higher plasma VEGF levels and increased HIF alpha-dependent induction of BNP production. ${ }^{34}$ Therefore, increased expression of HIF-2 alpha in RCC may stimulate BNP production. However, we found very low expression of BNP in both RCC tissues and normal kidney tissues in the present study. Therefore, further investigation is needed to elucidate why BNP and NT-proBNP levels are elevated and where these hormones are produced. In addition to its beneficial cardiac effects, BNP can act as an autocrine factor with antiproliferative, antifibrotic and direct cytoprotective effects. ${ }^{35} 36$ Thus, HIF-mediated induction of BNP production might be part of the local defence mechanism of the myocardium against hypoxic damage, although it is unclear how hypoxic upregulation of HIF-2 alpha in the tumour microenvironment influences the myocardium distant from the kidney.

\section{Cancer-related cardiac wasting}

It is well known that there is an association between advanced cancer and cachexia, which is potentially accompanied by cardiac wasting. ${ }^{13}$ The possible interaction between cachexia and heart failure in patients with cancer has recently attracted considerable attention. ${ }^{37}$ Cachexia is a multifactorial syndrome, in which weight loss is characterised by ongoing loss of skeletal muscle mass and progressive functional impairment. ${ }^{9}$ It has been postulated that cardiac dysfunction/atrophy parallels skeletal muscle atrophy in patients with cancer with cachexia. Heart failure may be a consequence of either progressive cachexia or cancer-induced/cancer-related cardiotoxic factors. Conversely, severe heart failure can result in cachexia, especially muscle wasting. Therefore, the onset of heart failure and cardiac cachexia could exacerbate cancer-induced cachexia. If elevation of the serum levels of BNP and NT-proBNP is postulated to suggest the presence of subclinical functional and morphological myocardial damage, it is likely that RCC itself might have some influence on such damage. If so, the decrease of serum BNP and NT-proBNP after tumour resection in patients with RCC might be associated with alleviation of stress on the heart. Since BNP and NT-proBNP both decreased after nephrectomy, it seems that upregulation of these hormones may be associated with cardiac defence mechanisms against the effects of cancer progression.

It was reported that some human small cell lung cancer cell lines had detectable BNP mRNA and BNP immunoreactivity. ${ }^{38}$ In contrast, in the preset study, expression of BNP using western blotting was very low in human RCC and normal kidney tissues. Similarly, it has been shown that any significant BNP production at a protein level was not detectable in human RCC cell lines. ${ }^{34}$ It therefore remains to be unanswered at this time whether human cancers produce BNP. Recent evidence suggests that cardiovascular paracrine mechanisms, such as the renin-angiotensin system (RAS), existing at local tissue sites have been implicated in tumorigenesis. ${ }^{39} 40$ Components of the RAS are expressed in several adult organs including the liver, kidney, pancreas, brain and reproductive organs, and local RAS may influence tissue angiogenesis, cellular proliferation, apoptosis and inflammation, and antagonism of the RAS mostly suppresses tumour growth, metastasis and angiogenesis in a broad range of experimental models of malignancy. ${ }^{39}$ RAS is fundamental in the overall regulation of cardiovascular homeostasis through the actions of important hormones, which regulate vascular tone, and specifically blood pressure through vasoconstriction and renal sodium and water retention. ${ }^{41}$ BNP and atrial natriuretic peptide (ANP) represent the most important endogenous RAS suppressing property by conferring cardiac, renal and vascular protection. ${ }^{41}$ Given an endogenous counter-regulatory constraint on the activity of the RAS and natriuretic peptides, such as BNP and ANP, therefore, we should study the expression of the RAS components in human RCCs in the forthcoming study in order to elucidate the roles of BNP/ANP and the RAS in this disease.

\section{Limitations}

The limitations of the present study included its retrospective design, a relatively small number of patients and a follow-up period that was too short to allow definite conclusions to be drawn. The present study did not 
address the molecular mechanisms by which HIF-2 alpha produced in the tumour microenvironment or by which VEGF acts on the myocardium to influence the serum levels of BNP and NT-proBNP. Without such information, we cannot determine the clinical meaning of elevated BNP and NT-proBNP levels in patients with RCC. Accordingly, further investigation is needed to determine where and how BNP and NT-proBNP are produced in response to RCC, increased tumour expression of HIF-2 alpha or elevation of serum VEGF. The results of such studies will be able to shed more light on the clinical meaning of elevated BNP and NT-proBNP levels in human cancer.

\section{CONCLUSION}

In conclusion, we found that the preoperative serum levels of BNP and NT-proBNP were not related to the expression of HIF-2 alpha in the primary tumour or the serum level of VEGF; both of these hormones might be clinically related to progression of RCC and a worse prognosis and showed a significant decrease after tumour resection, indicating that we should pay attention to the possibility of subclinical functional and structural damage to the myocardium in advanced RCC and provide insight into the cardiac defence mechanisms against the effects of cancer progression.

\section{Acknowledgements The authors thank Hitomi Yamazaki for her excellent} technical assistance in this study.

Contributors TK initiated the study, participated in its design and coordination, carried out the study, performed the statistical analysis and drafted the manuscript. YT, TU, KS, IS, KT, TN, TK, HY, HB, HA, YF and MY carried out the study. KIY participated in the design of the study and helped draft the manuscript. All authors read and approved the final manuscript.

Funding The study was funded by Japanese Science Progress Society KAKENHI (17K11156).

Competing interests None declared.

Patient consent Obtained.

Ethics approval This study was conducted in accordance with the Helsinki Declaration and was approved by the institutional Ethical Review Board of Dokkyo Medical University Hospital.

Provenance and peer review Not commissioned; externally peer reviewed.

Data sharing statement Individual participant data that underlie the results reported in this article, after deidentification (text, tables, figures and appendices).

Open Access This is an Open Access article distributed in accordance with the Creative Commons Attribution Non Commercial (CC BY-NC 4.0) license, which permits others to distribute, remix, adapt, build upon this work non-commercially, and license their derivative works on different terms, provided the original work is properly cited and the use is non-commercial. See: http://creativecommons.org/ licenses/by-nc/4.0/

(c) Article author(s) (or their employer(s) unless otherwise stated in the text of the article) 2018. All rights reserved. No commercial use is permitted unless otherwise expressly granted.

\section{REFERENCES}

1. Hanahan D, Weinberg RA. Hallmarks of cancer: the next generation. Cell 2011;144:646-74.

2. Abe H, Kamai T. Recent advances in the treatment of metastatic renal cell carcinoma. Int J Urol 2013;20:944-55.

3. Cancer Genome Atlas Research Network. Comprehensive molecular characterization of clear cell renal cell carcinoma. Nature 2013;499:43-9.
4. Gnarra JR, Tory K, Weng Y, et al. Mutations of the VHL tumour suppressor gene in renal carcinoma. Nat Genet 1994;7:85-90.

5. Wenger RH. Cellular adaptation to hypoxia: O2-sensing protein hydroxylases, hypoxia-inducible transcription factors, and O2regulated gene expression. Faseb J 2002;16:1151-62.

6. Maxwell PH, Wiesener MS, Chang GW, et al. The tumour suppressor protein VHL targets hypoxia-inducible factors for oxygen-dependent proteolysis. Nature 1999;399:271-5.

7. Kerbel RS. Tumor angiogenesis. N Engl J Med 2008;358:2039-49.

8. Ferrara N, Gerber HP, LeCouter J. The biology of VEGF and its receptors. Nat Med 2003;9:669-76.

9. Lippitz BE. Cytokine patterns in patients with cancer: a systematic review. Lancet Oncol 2013;14:e218-e228.

10. Goubran HA, Kotb RR, Stakiw J, et al. Regulation of tumor growth and metastasis: the role of tumor microenvironment. Cancer Growth Metastasis 2014;7:9-18.

11. Fearon K, Strasser F, Anker SD, et al. Definition and classification of cancer cachexia: an international consensus. Lancet Oncol 2011;12:489-95.

12. Fearon KC. Cancer cachexia and fat-muscle physiology. $N$ Engl J Med 2011;365:565-7.

13. Fearon KC, Glass DJ, Guttridge DC, et al. Cancer cachexia: mediators, signaling, and metabolic pathways. Cell Metab 2012;16:153-66.

14. Tisdale MJ. Cachexia in cancer patients. Nat Rev Cancer 2002;2:862-71.

15. von Haehling S, Doehner W, Anker SD. Nutrition, metabolism, and the complex pathophysiology of cachexia in chronic heart failure. Cardiovasc Res 2007;73:298-309.

16. von Haehling S, Lainscak M, Springer J, et al. Cardiac cachexia: a systematic overview. Pharmacol Ther 2009;121:227-52.

17. Anand IS, Fisher LD, Chiang YT, et al. Changes in brain natriuretic peptide and norepinephrine over time and mortality and morbidity in the Valsartan Heart Failure Trial (Val-HeFT). Circulation 2003;107:1278-83.

18. Koglin J, Pehlivanli S, Schwaiblmair M, et al. Role of brain natriuretic peptide in risk stratification of patients with congestive heart failure. J Am Coll Cardiol 2001;38:1934-41.

19. Mukoyama M, Nakao K, Hosoda K, et al. Brain natriuretic peptide as a novel cardiac hormone in humans. Evidence for an exquisite dual natriuretic peptide system, atrial natriuretic peptide and brain natriuretic peptide. J Clin Invest 1991;87:1402-12.

20. Richards AM, Crozier IG, Yandle TG, et al. Brain natriuretic factor: regional plasma concentrations and correlations with haemodynamic state in cardiac disease. Br Heart J 1993;69:414-7.

21. Muders F, Kromer EP, Griese DP, et al. Evaluation of plasma natriuretic peptides as markers for left ventricular dysfunction. Am Heart J 1997;134:442-9.

22. Tulevski II, Groenink M, van Der Wall EE, et al. Increased brain and atrial natriuretic peptides in patients with chronic right ventricular pressure overload: correlation between plasma neurohormones and right ventricular dysfunction. Heart 2001;86:27-30.

23. Burjonroppa SC, Tong AT, Xiao LC, et al. Cancer patients with markedly elevated B-type natriuretic peptide may not have volume overload. Am J Clin Oncol 2007;30:287-93.

24. Pavo N, Raderer M, Hülsmann M, et al. Cardiovascular biomarkers in patients with cancer and their association with all-cause mortality. Heart 2015;101:1874-80.

25. Weidemann A, Klanke B, Wagner M, et al. Hypoxia, via stabilization of the hypoxia-inducible factor HIF-1alpha, is a direct and sufficient stimulus for brain-type natriuretic peptide induction. Biochem $J$ 2008;409:233-42.

26. Weber M, Hamm C. Role of B-type natriuretic peptide (BNP) and NTproBNP in clinical routine. Heart 2006;92:843-9.

27. Fuhrman SA, Lasky LC, Limas C. Prognostic significance of morphologic parameters in renal cell carcinoma. Am J Surg Pathol 1982;6:655-64.

28. Sobin LH, Gospodarowicz MK, Wittekind CH. UICC. International union against cancer. TNM classification of malignant tumors. 7th edn. New York: Wiley-Liss, 2009:255-7.

29. Mizuno $\mathrm{T}$, Kamai $\mathrm{T}$, Abe $\mathrm{H}$, et a/Clinically significant association between the maximum standardized uptake value on ${ }^{18}$ F-FDG PET and expression of phosphorylated Akt and S6 kinase for prediction of the biological characteristics of renal cell cancerBMC Cancer 2015;15:1097.

30. Popat J, Rivero A, Pratap P, et al. What is causing extremely elevated amino terminal brain natriuretic peptide in cancer patients? Congest Heart Fail 2013;19:143-8.

31. Liao L, Testa JR, Yang H. The roles of chromatin-remodelers and epigenetic modifiers in kidney cancer. Cancer Genet 2015;208:206-14. 
32. Kaelin WG. The von Hippel-Lindau protein, HIF hydroxylation, and oxygen sensing. Biochem Biophys Res Commun 2005;338:627-38.

33. Toschi A, Lee E, Gadir N, et al. Differential dependence of hypoxiainducible factors 1 alpha and 2 alpha on mTORC1 and mTORC2. Biol Chem 2008;283:34495-9.

34. Papazisis KT, Kontovinis LF, Papandreou CN, et al. Brain natriuretic peptide precursor (NT-pro-BNP) levels predict for clinical benefit to sunitinib treatment in patients with metastatic renal cell carcinoma. BMC Cancer 2010;10:489.

35. Tamura N, Ogawa $\mathrm{Y}$, Chusho $\mathrm{H}$, et al. Cardiac fibrosis in mice lacking brain natriuretic peptide. Proc Natl Acad Sci U S A 2000;97:4239-44.

36. D'Souza SP, Yellon DM, Martin C, et al. B-type natriuretic peptide limits infarct size in rat isolated hearts via KATP channel opening. Am J Physiol Heart Circ Physiol 2003;284:H1592-600.
37. Kazemi-Bajestani SM, Becher H, Fassbender K, et al. Concurrent evolution of cancer cachexia and heart failure: bilateral effects exist. J Cachexia Sarcopenia Muscle 2014;5:95-104.

38. Ohsaki Y, Gross AJ, Le PT, et al. Human small cell lung cancer cells produce brain natriuretic peptide. Oncology 1999;56:155-9.

39. George AJ, Thomas WG, Hannan RD. The renin-angiotensin system and cancer: old dog, new tricks. Nat Rev Cancer 2010;10:745-59.

40. Ager El, Neo J, Christophi C. The renin-angiotensin system and malignancy. Carcinogenesis 2008;29:1675-84.

41. Romero CA, Orias M, Weir MR. Novel RAAS agonists and antagonists: clinical applications and controversies. Nat Rev Endocrinol 2015;11:242-52. 